\title{
Analisa Perbedaan Pengukuran Koordinat Dalam Ruangan dengan TLS Topcon GLS-2000
}

\author{
Alif Fariq'an Setiawan dan Agung Budi Cahyono \\ Departemen Teknik Geomatika, Fakultas Teknik Sipil, Lingkungan dan Kebumian \\ Institut Teknologi Sepuluh Nopember (ITS) \\ e-mail: agungbc@geodesy.its.ac.id
}

\begin{abstract}
Abstrak-TLS (Terrestrial Laser Scanner) merupakan salah satu alat yang digunakan untuk mengakuisisi data dengan cara memindai permukaan obyek, yang dapat diaplikasikan pada pemodelan 3D, perhitungan volume dan pengukuran terestris. Dalam penelitian ini dilakukan analisa data pengukuran koordinat TLS dengan ETS (Electronic Total Station). Pada proses pelaksanaannya, penelitian ini dilakukan pada dua ruangan yang memiliki ukuran dan dimensi yang berbeda, yai tu Ruang I dan Ruang II. Akuisisi data ETS dilakukan dengan melakukan proses pengukuran koordinat pada target yang te lah tersebar didalam ruangan. Sedangkan untuk akuisisi data TLS dilakukan dengan melakukan pemindaian pada setiap ruangan yang telah tersebar targetnya. Selisih nilai koordinat dari data TLS dengan ETS dianggap sebagai nilai kesalahan sistematis. Dari hasil penelitian menunjukkan bahwa untuk Ruang I, selisih nilai koordinat yang dihasilkan adalah koordinat $X$ sebesar 0.003 $\mathrm{m}$, koordinat $\mathrm{Y}$ sebesar $0.004 \mathrm{~m}$, dan koordinat $\mathrm{Z}$ sebesar 0.0010 m. Sedangkan pada Ruang II, selisih nilai koordinat yang dihasilkan adalah sebesar koordinat $X$ sebesar $0.003 \mathrm{~m}$, koordinat $Y$ sebesar $0.004 \mathrm{~m}$, dan koordinat $\mathrm{Z}$ sebesar $0.004 \mathrm{~m}$. Hal ini menunjukkan bahwa pengukuran TLS di kedua ruangan pada posisi planimetris tidak terpengaruh oleh ukuran dan dimensi, sedangkan pada posisi elevasi memiliki selisih sebesar 6 mm.
\end{abstract}

Kata Kunci-Kesalahan Sistematis, Terrestrial Laser Scanner, ETS.

\section{PENDAHULUAN}

$\mathrm{T}$ ERRESTRIAL Laser Scanner merupakan salah satu alat modern yang menunjang perkembangan permodelan 3 dimensi (3D). Permodelan 3D ini digunakan untuk memodelkan bangunan atau suatu wilayah sehingga terbentuk sebuah peta 3D yang dapat digunakan untuk banyak hal. Aplikasi penggunaan TLS semakin meluas pada kalangan surveyor dan ahli ilmu kebumian karena TLS ini mampu mengambil banyak data titik yang sangat rapat dan akurat dalam waktu yang cepat serta teknik yang bisa dikatakan mudah. Teknologi ini merupakan alat pencitraan aktif yang menggunakan laser sebagai medianya untuk mendapatkan satu set titik 3D (point clouds) dari suatu permukaan atau objek dalam satu kali pengamatan .

Hasil dari permodelan 3D ini telah banyak diterapkan diberbagai aplikasi dalam bidang rekayasa, untuk pengadaan data as-built dan pemodelan dalam aplikasi transportasi, termasuk pengukuran tanah, studi arkeologi, arsitektur, struktur jembatan, dan survey jalan raya, dan bahkan untukk analisis tempat kejadian perkara (TKP) [1]. Data koordinat 3D
TLS tersebut diperoleh dari data sudut dari backsight ke objek dan data jarak yang dihitung dari waktu tempuh laser dan cepat rambat laser. Suatu alat ukur pasti memiliki nilai kesalahan. Salah satunya dari alat itu sendiri, sehingga dapat mempengaruhi hasil pengukuran atau menjadikan hasil dan data pengukuran menjadi salah [2]. Untuk mengetahui nilai kesalahan point clouds dari TLS itu dapat dibandingkan dengan alat ETS. Hal ini dilakukan untuk memahami seperti apa akurasi antara ETS dan TLS ketika data ETS menjadi data acuan [3].

Pada penelitian sebelumnya yang berjudul Mekanisme Kalibrasi TLS, kesalahan data TLS terhadap ETS disebabkan oleh beberapa hal. Pertama perbedaan jenis dan kelas rangefinder yang digunakan pada penelitian tersebut, kedua perbedaan dalam jumlah pengukuran kedua alat yang berbeda. Karena hal itu dibutuhkan penelitian lanjutan mengenai penerapan pengaruh besarnya kesalahan TLS terhadap data ukuran ETS [4]. Dalam penelitian ini, penulis membahas mengenai suatu analisa hasil pengukuran koordinat point cloud pada alat ukur Terestrial Laser Scanner kemudian membandingkannya dengan data koordinat $(\mathrm{X}, \mathrm{Y}, \mathrm{Z})$ yang didapat dari ETS Reflektorless.

\section{METODOLOGI PENELITIAN}

\section{A. Lokasi Penelitian}

Lokasi penelitian ini dilakukan pada dua tempat yang memiliki ukuran yang berbeda. Yaitu ruang kelas 104 (Ruang I) Teknik Geomatika ITS dan ruang kantor PT. ASABA Surveying (Ruang II). Lokasi penelitian ditunjukan pada gambar berikut ini :

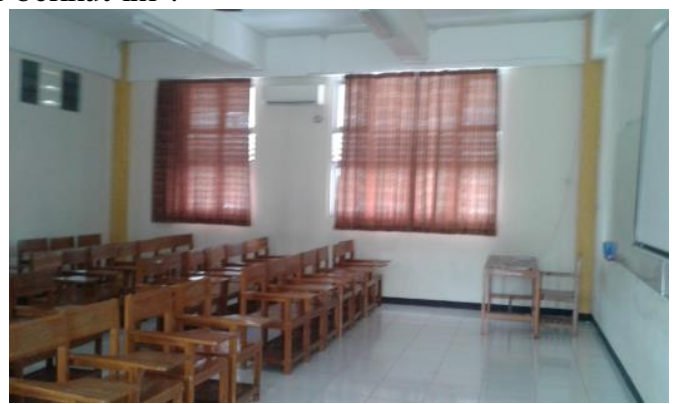

Gambar 1. Ruang Kelas 104 (Ruang I) 


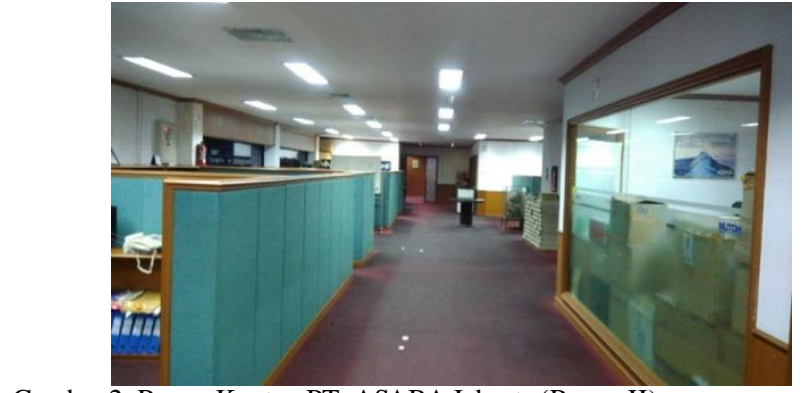

Gambar 2. Ruang Kantor PT. ASABA Jakarta (Ruang II)

\section{B. Data dan Peralatan}

\section{Data}

Data yang digunakan adalah data pengukuran langsung di dua lokasi penelitian. Data pengukuran yang digunakan adalah data pengukuran koordinat yang didapat dari dua alat yang berbeda yaitu TLS dan ETS. Data yang diamati adalah data jarak sudut dari ETS yang diolah menjadi data koordinat. Sedangkan data TLS yang diamati adalah data hasil pemindain yang diolah kemudian diamati data koordinat yang dihasilkan.

\section{Peralatan}

Peralatan yang digunakan dibagi menjadi dua, yakni perangkat keras dan perangkat lunak. Perangkat keras terdiri dari TLS Topcon GLS 2000 , ETS Reflektorless Hi Target ZTS-320R, target koordinat, komputer dan printer. Perangkat lunak terdiri dari Microsoft Office sebagai pengolah data dokumen dan Maptek I-Site Studio 7.0 sebagai pengolah data laser scanner.

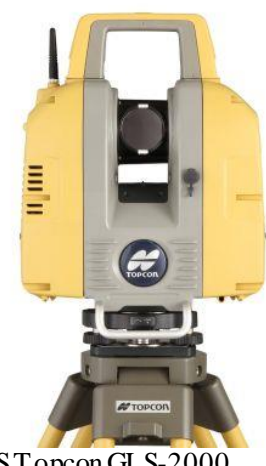

Gambar 3.TLST opcon GLS-2000

\section{Ruang Studi}

Pada penelitian ini dilakukan pada dua tempat yang memiliki bentuk dan ukuran yang berbeda yaitu Ruang I dan Ruang II. Berikut ini ilustrasi dari kedua ruangan tersebut :

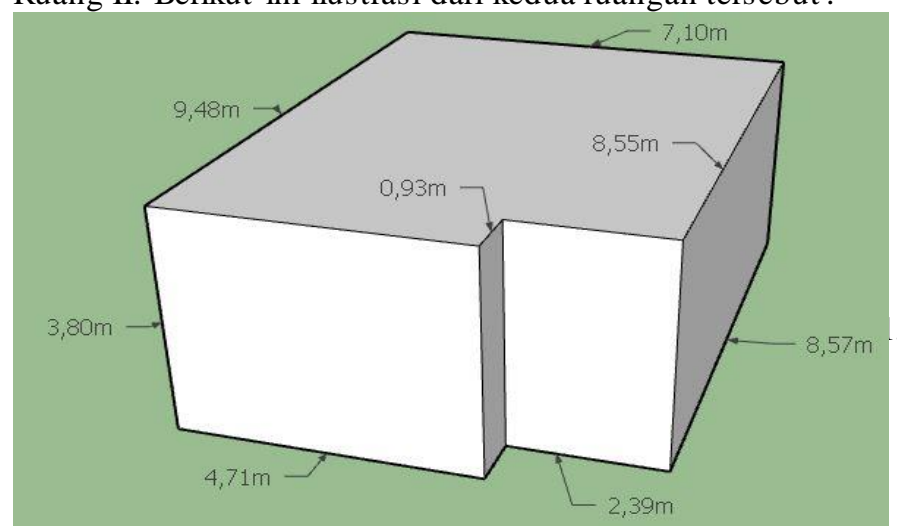

Gambar 4. Dimensi Ruang I

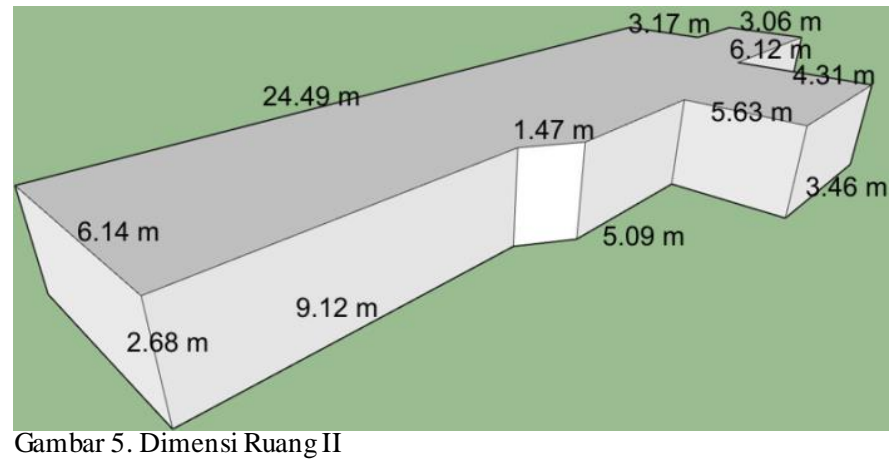

\section{Diagram Alir Penelitian}

Berikut adalah diagram alir penelitian seperti pada Gambar berikut ini :

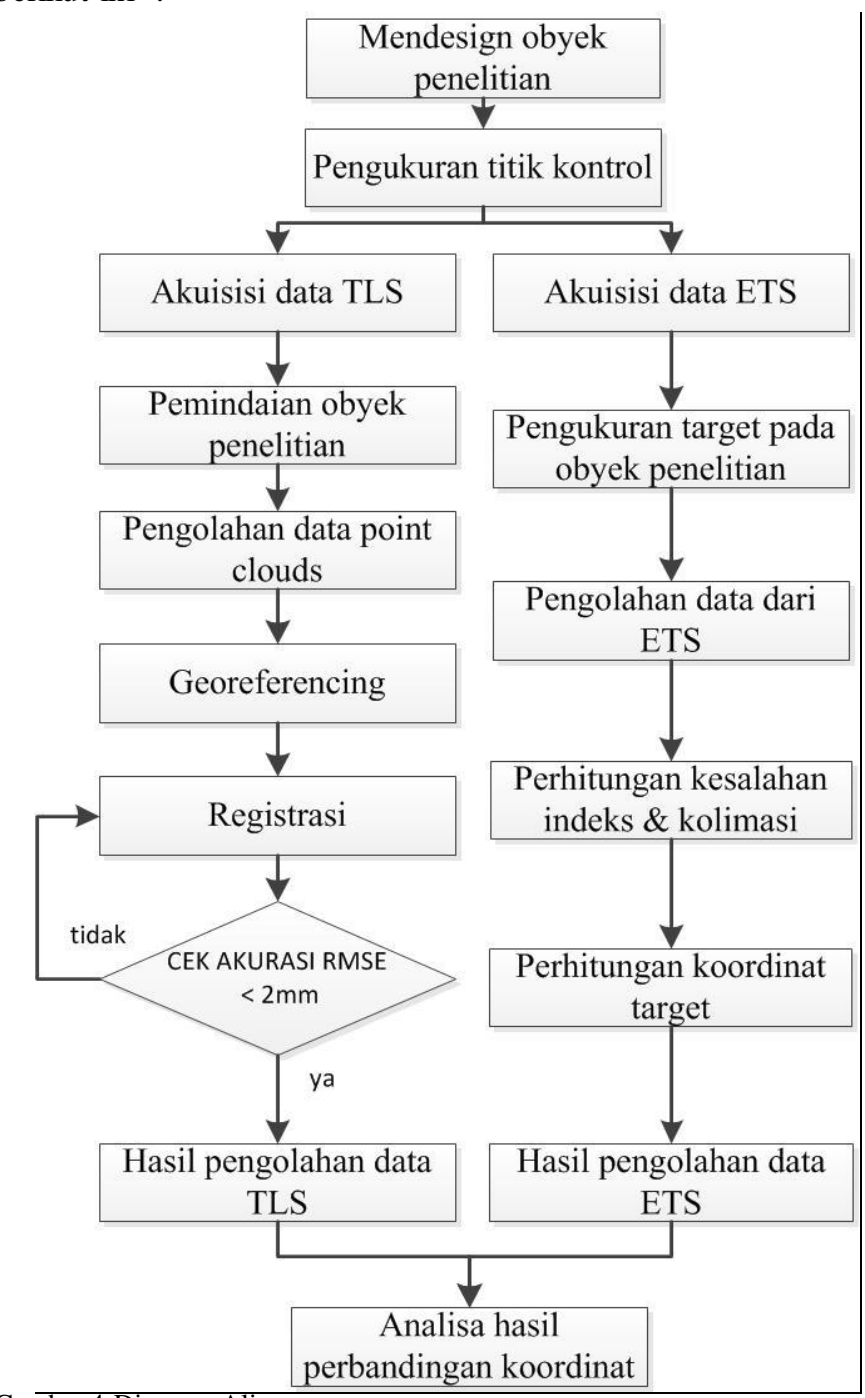

Gambar 4.Diagram Alir

Penjelasan diagram alir di atas sebagai berikut

Mendesign Obyek Penelitian

Terlebih dahulu mempersiapkan obyek penelitian yang digunakan, dengan menata ruangan agar titik control dan titik target dapat dipasang dan tidak terhalang. Titik control itu nantinya akan digunakan untuk berdiri alat TLS dan ETS. Kemudian titik target target ini ditempel secara merata pada 
ruangan .

2. Pengukuran Titik Kontrol

Pengukuran ini dilakukan untuk mengetahui titik koordinat dimana posisi alat berdiri. Pengukuran titik control ini menggunakan sistem koordinat local. Toleransi pengukuran polygon yang digunakan adalah toleransi kesalahan penutup sudut yaitu i $\sqrt{ }$, sebesar 4 detik dan juga toleransi pengukuran linier sebesar 1/5000.

3. Akuisisi Data

Dalam penelitian ini, proses akuisisi data menggunakan TLS dilakukan di titik control yang telah diukur.TLS melakukan proses scanning pada kedua ruangan. Pengumpulan data juga dilakukan dengan alat ETS, pengukurannya dilakukan dari posisi yang sama seperti proses akuisisi data menggunakan TLS. Pengukuran dengan ETS dilakukan dengan membidik target pada titik tengah keseluruhan target yang akan diukur. Data hasil ukuran ETS hanyalah data sudut horizontal, sudut vertikal yang berupa sudut miring, dan jarak miring antara ETS dengan target yang tersebar.

4. Pengolahan data

Untuk pengolahan data TLS yang merupakan hasil scanning Ruang 1 dan Ruang II , harus melalui beberapa tahap yaitu pertama proses tahap Georeferencing yaitu proses menambahkan sistem koordinat pada point clouds yang telah dihasilkan. Hal tersebut dilakukan agar hasil data dari TLS memiliki sistem koordinat yang seragam dengan hasil data dari ETS sehingga perbandingan hasil ukuran koordinat dapat dilakukan. Kemudian tahap filtering, yaitu tahap yang bertujuan untuk melakukan pengurangan titik-titik point cloud yang tidak digunakan atau bis a disebut dengan noise, noise ini dapat berpengaruh pada proses Registrasi karena semakin banyak noise yang ada dapat mempengaruhi hasil RMS error dari proses registrasi. Tahap selanjutnya yaitu Registrasi, yaitu proses menyatukan beberapa hasil scanning yang memiliki sistem koordinat yang berbeda agar menjadi satu sistem koordinat yang seragam. Kemudian diamati koordinatnya pada bagian tengah target sehingga dapat diketahui nilai koordinat target tersebut.

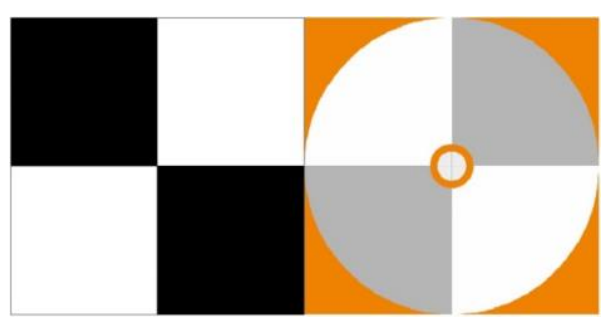

Gambar 5. T arget Ruang I (kiri) \& Target Ruang II (kanan)

Untuk pengolahan data ETS melalui bebeerapa tahap yaitu perhitungan kesalahan indeks alat dan kesalahan kolimasi, perhitungan sudut horizontal dan sudut vertikal sebenarnya, perhitungan azimuth, perhitungan jarak mendatar dan jarak vertikal, kemudian dilakukan perhitungan koordinat target.

5. Analisa Perbandingan

Proses analisa koordinat TLS dilakukan dengan cara membandingkan data koordinat yang didapat dengan data hasil pengukuran ETS sebagai data acuan yang dianggap benar. Kemudian dianalisa berapa nilai perbedaannya dan didapatkan hasilnya secara keseluruhan untuk masing masing obyek penelitian.

\section{HASIL DAN ANALISA}

\section{A. Hasil Pengukuran Titik Kontrol}

Dalam penelitian ini pengukuran titik kontrol digunakan untuk mengetahui berapa nilai koordinat yang digunakan untuk berdiri alat kedua alat tersebut. Pada kedua obyek penelitian menggunakan 4 titik control, berikut ini adalah koordinat titik kontrol di kedua ruangan :

Tabel 1.

Koordinat Titik Kontrol

\begin{tabular}{cccc}
\hline \hline \multirow{2}{*}{ No Titik } & \multicolumn{3}{c}{ Ruang I } \\
\cline { 2 - 4 } & $\mathrm{X}$ & $\mathrm{Y}$ & $\mathrm{Z}$ \\
\hline 1 & 0 & 0 & 0 \\
2 & -0.013 & -3.614 & 0.009 \\
3 & 2.404 & -3.624 & 0.007 \\
4 & 2.415 & 0 & 0.002 \\
\hline Penutup Sudut & \multicolumn{4}{c}{$1 / 29270.312$} \\
\hline Kesalahan Linier & $\mathrm{X}$ & $\mathrm{K}$ Yang II \\
\hline No Titik & 1000 & 1000 \\
& 998.849 & 1004.713 & 100.017 \\
2 & 997.973 & 1009.884 & 100.018 \\
3 & 997.104 & 1014.761 & 100.008 \\
4 & \multicolumn{4}{|c}{} \\
\hline \hline
\end{tabular}

Ruang I dan ruang II menggunkan metode pengukuran titik control yang berbeda. Pada ruang I enggunakan poligin tertutup sedangkan ruang II menggunakan polygon terbuka. Nilai toleransi penutup sudut yang diperbolehkan untuk ruang I sebesar 5 detik, dan toleransi kesalahan linier sebesar 1/5000. Nilai kesalahan penutup sudut dan penutup linier pada ruang I memenuhi nilai toleransi yang telah ditentukan karena nilai keduanya lebih kecil dari nilai yang telah ditentukan. Koreksi penutup tinggi tidak digunakan karena proses pengukuran beda tinggi yang menggunakan ETS. Sedangkan untuk ruang II tidak memiliki nilai kesalahan karena metode pengukuran titik control pada ruang II menggunakan polygon terbuka yang tidak memiliki nilai toleransi.

\section{B. Hasil Pengukuran Koordinat TLS}

Untuk mendapatkan nilai koordinat pada TLS harus melalui beberapa tahap terlebih dahulu yaitu Georeferening, Filtering dan Registrasi. Pada Ruang I menggunakan 30 target, sedangkan Ruang II hanya menggunakan 9 target. Berikut ini merupakan point cloud yang dihasilkan TLS

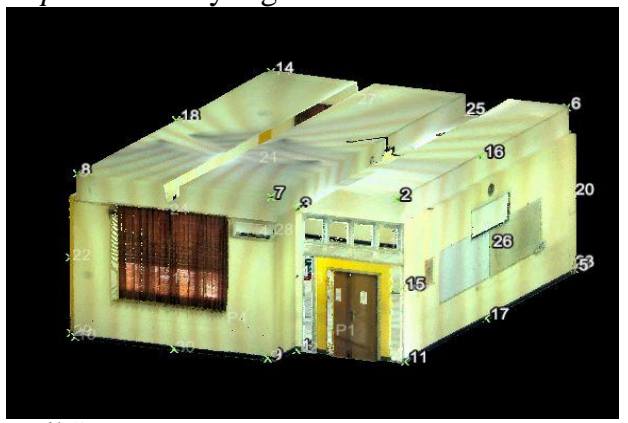

Gambar 6. Hasil Scan Ruang I 


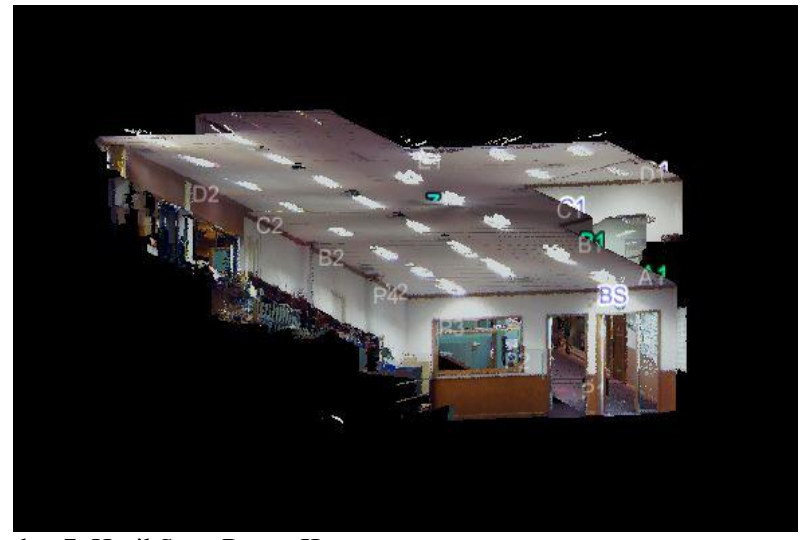

Gambar 7. Hasil Scan Ruang II

\section{Hasil Pengukuran Koordinat ETS}

Data koordinat dari ETS didapatkan dari pengukuran detail pada target-target yang tersebar pada ruangan. Untuk mengurangi kesalahan dari instrument maka ditambahkan koreksi kesalahan indeks dan kesalahan kolimasi. Pada ruang I koreksi kesalahan indeks ditambahkan sebesar -6.5 " dan koreksi kolimasi sebesar -5.5". Sedangkan untuk ruang II koreksi kesalahan indeks ditambahkan sebesar - -8.25 " dan koreksi kolimasi sebesar-2.25".

\section{Hasil Perbandingan Koordinat Target}

Berdasarkan data koordinat target yang didapatkan dari dua alat yaitu TLS dan ETS memiliki nilai yang berbeda, berikut ini merupakan nilai perbedaannya:

Tabel 1.

Perbedaan Koordinat Target Ruang I

\begin{tabular}{cccc}
\hline \hline No Point & $\Delta \mathrm{x}(\mathrm{m})$ & $\Delta \mathrm{y}(\mathrm{m})$ & $\Delta \mathrm{Z}(\mathrm{m})$ \\
\hline 1 & 0.001 & 0.002 & 0.003 \\
2 & 0.003 & 0.003 & 0.006 \\
3 & 0.004 & 0.004 & 0.003 \\
4 & 0.003 & 0.005 & 0.009 \\
5 & 0.004 & 0.009 & 0.008 \\
6 & 0.001 & 0.005 & 0.011 \\
7 & 0.006 & 0.003 & 0.018 \\
8 & 0.001 & 0.005 & 0.020 \\
9 & 0.003 & 0.008 & 0.010 \\
10 & 0.002 & 0.003 & 0.012 \\
11 & 0.009 & 0.005 & 0.011 \\
12 & 0.003 & 0.003 & 0.002 \\
13 & 0.002 & 0.004 & 0.012 \\
14 & 0.002 & 0.004 & 0.005 \\
15 & 0.004 & 0.003 & 0.009 \\
16 & 0.002 & 0.008 & 0.019 \\
17 & 0.008 & 0.004 & 0.007 \\
18 & 0.004 & 0.002 & 0.002 \\
19 & 0.001 & 0.003 & 0.005 \\
20 & 0.002 & 0.010 & 0.012 \\
21 & 0.003 & 0.004 & 0.018 \\
22 & 0.004 & 0.004 & 0.012 \\
23 & 0.004 & 0.005 & 0.008 \\
24 & 0.004 & 0.003 & 0.016 \\
25 & 0.003 & 0.002 & 0.005 \\
26 & 0.003 & 0.001 & 0.019 \\
\hline \hline
\end{tabular}

Lanjutan Tabel 1.

\begin{tabular}{cccc}
\hline \hline No Point & $\Delta \mathrm{x}(\mathrm{m})$ & $\Delta \mathrm{y}(\mathrm{m})$ & $\Delta \mathrm{Z}(\mathrm{m})$ \\
\hline 27 & 0.006 & 0.002 & 0.012 \\
28 & 0.002 & 0.003 & 0.010 \\
29 & 0.003 & 0.009 & 0.001 \\
30 & 0.004 & 0.004 & 0.002 \\
\hline \hline
\end{tabular}

Tabel 2.

Perbedaan Koordinat Target Ruang II

\begin{tabular}{cccc}
\hline \hline No Point & $\Delta \mathrm{x}(\mathrm{m})$ & $\Delta \mathrm{y}(\mathrm{m})$ & $\Delta \mathrm{z}(\mathrm{m})$ \\
\hline A1 & 0.002 & 0.003 & 0.002 \\
A2 & 0.003 & 0.006 & 0.010 \\
B1 & 0.005 & 0.004 & 0.005 \\
B2 & 0.001 & 0.003 & 0.007 \\
C1 & 0.002 & 0.007 & 0.000 \\
C2 & 0.003 & 0.001 & 0.005 \\
D1 & 0.004 & 0.008 & 0.001 \\
D2 & 0.001 & 0.006 & 0.003 \\
E1 & 0.006 & 0.001 & 0.003 \\
\hline \hline
\end{tabular}

Rata-rata nilai perbedaan koordinat antara TLS dan ETS pada Ruang I adalah koordinat X sebesar $0.003 \mathrm{~m}$, koordinat Y sebesar $0.004 \mathrm{~m}$, dan koordinat Z sebesar 0.010 . Sedangkan pada Ruang II adalah koordinat X sebesar $0.003 \mathrm{~m}$, koordinat Y sebesar $0.004 \mathrm{~m}$, dan koordinat Z sebesar $0.004 \mathrm{~m}$.

\section{KESIMPULAN}

Adapun kesimpulan yang diambil dari penelitian ini adalah sebagaiberikut :

Nilai rata-rata selisih koordinat antara TLS dan ETS pada Ruang I yaitu pada koordinat X sebesar $0.003 \mathrm{~m}$, koordinat $\mathrm{Y}$ sebesar $0.004 \mathrm{~m}$ dan koordinat $\mathrm{Z}$ sebesar $0.010 \mathrm{~m}$. Sedangkan untuk Ruang II yaitu pada koordinat X sebesar $0.003 \mathrm{~m}$, koordianat $\mathrm{Y}$ sebesar $0.004 \mathrm{~m}$ dan koordinat $\mathrm{Z}$ sebesar 0.004 $\mathrm{m}$.

2. Nilai selisih koordinat terbesar pada koordinat $\mathrm{X}$ sebesar $0.009 \mathrm{~m}$, sedangkan pada koordinat Y sebesar 0.010 $\mathrm{m}$, dan untuk koordinat $\mathrm{Z}$ senilai $0.019 \mathrm{~m}$. Untuk selisih terkecilnya pada koordinat $X$ dan $Y$ memiliki nilai yang sama yaitu $0.001 \mathrm{~m}$, sedangkan koordinat $\mathrm{Z}$ memiliki nilai $0.000 \mathrm{~m}$.

3. Pengukuran TLS di kedua ruangan pada posisi planimetris tidak terpengaruh oleh ukuran ataupun dimensi karena memiliki nilai rata-rata kesalahan yang hampir sama, namun untuk posisielevasi memiliki selisih sebesar $6 \mathrm{~mm}$.

\section{UCAPAN TERIMA KASIH}

Penulis A.F.S. mengucapkanan terima kasih kepada PT. ASABA Surveying yang telah meminjamkan alat TLS Topcon GLS-2000 untuk kelangsungan penelitian ini.

\section{DAFTAR PUSTAKA}

[1] J. Hiremagalur, S. Yen, K, T. A. Lasky, and B. Ravani, "Testing and Performance Evaluation of Fixed Terrestrial 3D Laser Scanning 
JURNAL TEKNIK ITS Vol. 7, No. 1 (2018), 2337-3520 (2301-928X Print)

Systems for Highway Applications," in Transportation Re search Board 88th Annual Meeting 2009, 1995, p.9.

[2] H. Ingensand, A. Ryf, and T. Schulz, "Performances and Experiences in Terrestrial Laser Scanning," Opt.3DMeas. Tech. V, vol. 6, pp. 236-243, 2003.

[3] E. Liscio, A. Hayden, and J. Moody, "A Comparison of the
Terestrial Laser Scanner \& Total Station for Scane Documentation," J Assoc Crime Scene Reconstr, vol. 20,pp. 1-8, 2015.

[4] R. Adhitiaputra, Mekanisme Kalibrasi Terestrial Laser Scanner. Bandung: IT B, 2013. 